Fig. 1 Folding process of pantyhose

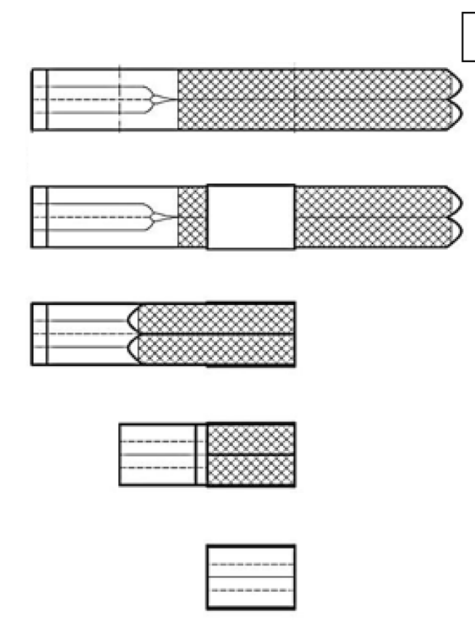

(a) top view

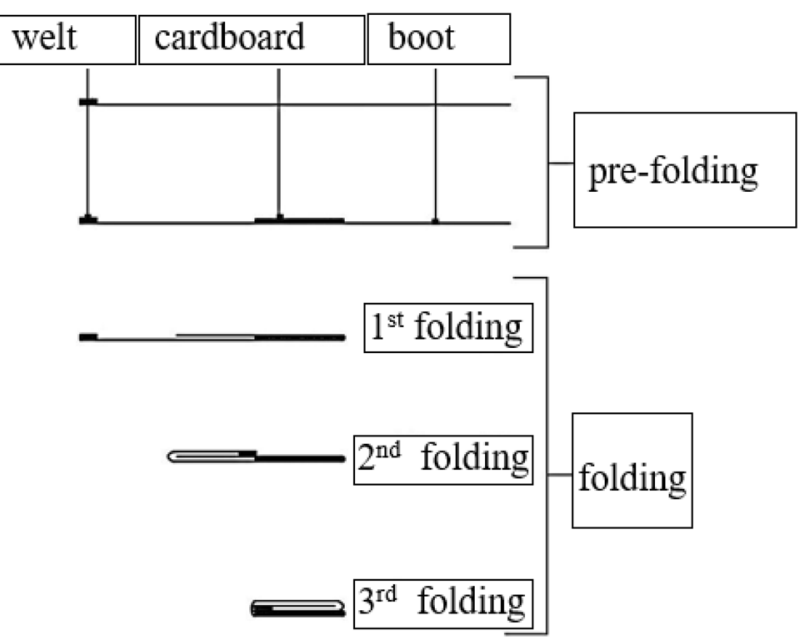

(b) front view packaging process. Therefore, cardboard placing is important for automatic packaging machine.

Vacuum picking is widely used for sheet picking in practical industrial application. A specific case of pantyhose packaging is shown in Fig. 2, the magazine is inclined at a certain angle to ensure the close contact between the sucker and the cardboard stock under its own gravity. On the other hand, two baffles of a certain height are needed at the front end of the magazine to prevent the cardboards sliding down. The cardboard deforms to break away from the constraint of the baffles under the action of the sucker. Considering that the cardboard used in packaging is usually made of paper whose stiffness and elasticity are limited, the design of the picking system is the key to avoid failures, damages and multiple feeds in the vacuum picking process.

Some research studied the mechanical performance of sheets with the help of relevant elasticity theory and special designed experiments. Biancolini [2] studied the buckling behavior of corrugated paper packages by means of an experimental and theoretical analysis. Mechanical behavior of paperboard was firstly evaluated experimentally, then a local geometry FEM model, able to reproduce buckling loads obtained experimentally in the standard

Fig. 2 Scheme of vacuum picking

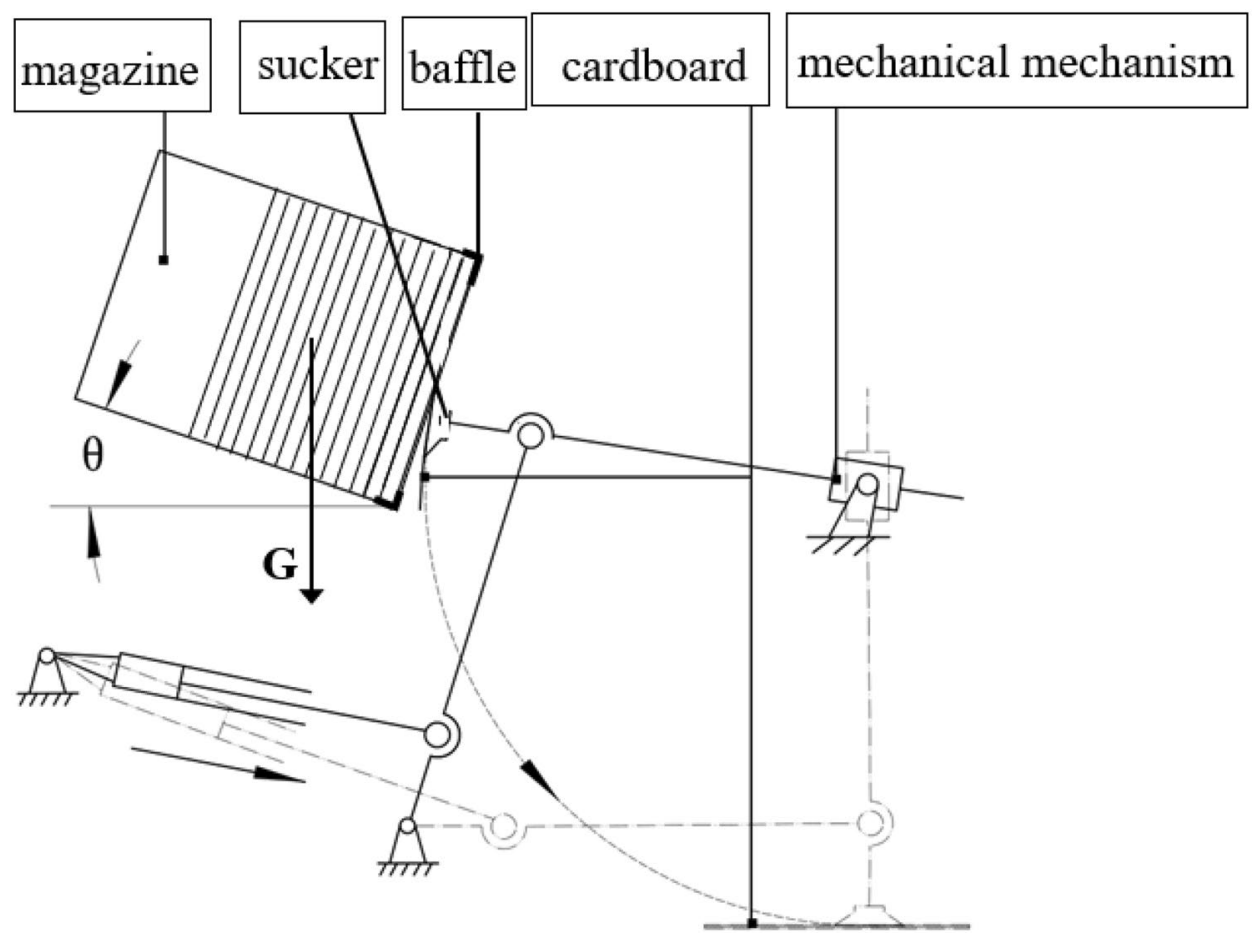


edge compression test with a very good accuracy, was developed to accurately predict the experimental data of incipient buckling observed during the standard box compression test. Wen [3] tested four kinds of thickness paperboard according to longitudinal and transverse direction respectively, the curve of flexure load deflection was analyzed, the relationship between flexure yield load, flexure strength of face sheet, shear strength of core and thickness and direction of paperboard was studied. Hua [4] investigated the edge effect and the influence on edgewise compressive strength of the two sandwich paperboards by experimental and numerical simulation methods, constructed the finite element models of corrugated fiberboard and honeycomb paperboard and the edge enhancement finite element models of the two paperboards. Pathare [5] investigated the effects of different storage conditions on the mechanical performance of two types of ventilated packaging, the effects of storage condition on moisture content of package was also studied. Luong [6] estimated the repetitive shock induced damages leading to cumulative fatigue on corrugated cardboard boxes experimentally and numerically, a finite element approach is proposed using an elastoplastic homogenization model for corrugated cardboard to computationally determine the damage boundary curve. Wang [7] investigated the bending fatigue behavior of B-flute and C-flute corrugated paperboard under cycle loading through three-point bending fatigue test. Li [8] experimentally and numerically investigated the interface fracture behavior in pure crack opening mode and sliding mode in the paperboard creasing and folding process. Guo [9] evaluated the dynamic shock cushioning characteristics and vibration transmissibility of X-PLY corrugated paperboards by a series of experimental studies on the drop shock tester and vibration tester, the experimental formulas of dynamic cushioning curves, and the analysis of peak frequencies, vibration transmissibility and damping ratios were established. Park [10] carried out vibration transmissibility test and drop shock test for the transmissibility-frequency curve and dynamic cushion curve of corrugated fiberboard. Bivainis [11] used a standard triangular prism, corrugated paperboard fixation plates and a universal tension-compression machine to investigate the impact of corrugated paperboard structure and other parameters on the puncture resistance of corrugated paperboard.

Rather than the features of fiber-based material including corrugated paperboard, paperboard, corrugated fiberboard and honeycomb paperboard studied in the literature above, in this paper it regards cardboard placing as a systematic operation, and focuses on the behavior of the cardboard during the specific vacuum picking process. Baffle height, back pressure and friction between sheets are taken into consideration as the three main variables of the system which may be critical in successful operation of cardboard picking. These variables in the vacuum picking system are evaluated through simulations and experiments. The objective is to analyze the cardboard behavior during the vacuum picking process and the interactions of baffle height, back pressure and friction in successful operation of cardboard picking.

This paper is organized as follows. After the introduction of the related literature in Sect. 1, the method to establish and solve the Finite Element Model are studied in Sect. 2. Then the Finite Element Model is used to evaluate the variables of the system in Sect. 3. In Sect. 4, experiments are conducted to verify the simulations. In Sect. 5, the results of the experiments and simulations are compared with results presented in relevant papers. In Sect. 6, some conclusions are given.

\section{Modeling and solution}

The cardboard deforms and separates itself from the constraint of the baffles under a certain adsorption force. In the following, the relationship between the cardboard behavior and the variables of the system is evaluated through simulations.

\subsection{Establishment of the model}

The solid model is established as shown in Fig. 3. As listed in Table 1, the dimensions and property values of the cardboard, baffles, stock and suckers are consistent with the real ones, Shell 181 element and Solid185 element of ANSYS are chosen to mesh them. The type of surface contact between the cardboard and the baffles is no separate, which keeps cardboard in close contact with the baffles during the picking process. The type of surface contact between the cardboard and the suckers is bond, which ensures no relative move during the picking process. The type of surface contact between the cardboard and the stock is standard, which allows the two to be separated.

\subsection{Solution of the model}

The method and convergence criterion are the key to solve this contact problem.

\subsubsection{Method}

Assume that $K$ is the stiffness matrix of the picking system, $u$ represents the corresponding displacement of the picking system while $q$ is the exerted load, its variation of potential energy is 
Fig. 3 Model of the simulations

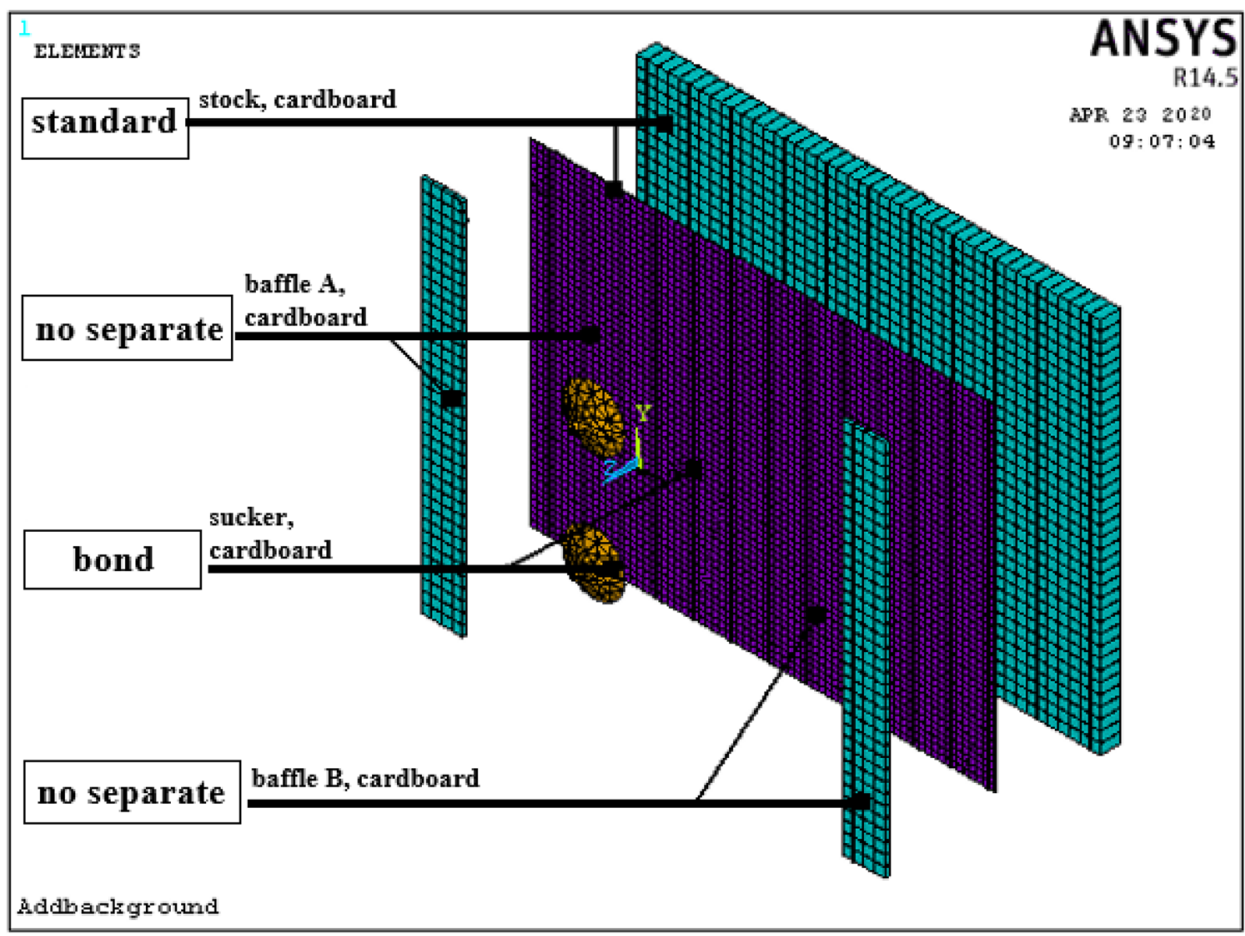

Table 1 Property values

\begin{tabular}{llllll}
\hline Solid model & Cardboard & Baffle & Stock & Solid model & Sucker \\
\hline x-dimension $(\mathrm{mm})$ & 220 & $2,3,4,5,6,7,8$ & 220 & Diameter $(\mathrm{mm})$ & 35 \\
y-dimension $(\mathrm{mm})$ & 160 & 160 & 160 & & \\
Thickness $(\mathrm{mm})$ & 0.46 & 4 & 92 & Distance ratio & 0.3 \\
Elastic modulus $(\mathrm{GPa})$ & $2 \mathrm{E}-3$ & 210 & 210 & Elastic modulus $(\mathrm{GPa})$ & $7.84 \mathrm{E}-3$ \\
Poisson's ratio & 0.353 & 0.269 & 0.269 & Poisson's ratio & 0.47 \\
Meshing & Shell181 & Shell181 & Shell181 & Meshing & Solid185 \\
\hline
\end{tabular}

$\delta \Pi=[K]\{u\}-\{q\}$

In order to achieve the balance of the picking system [12-17], there should be the following relationship

$[K]\{u\}=\{q\}$

If the load is divided into a series of components and exerted gradually, the stiffness matrix is amended at each step, there will be the new equilibrium equation for the picking system as

$\left[K_{i}\right]^{T}\left\{\Delta u_{i+1}\right\}=\left\{\Delta q_{i+1}\right\}$

$\left\{u_{i+1}\right\}=\left\{u_{i}\right\}+\left\{\Delta u_{i}\right\}$

here $\Delta u_{i}$ is the displacement increment reflecting the deformation of the picking system. In order to eliminate the cumulative deviation, it is still necessary to amend Eq. (4) as

$$
\left\{u_{i+1}\right\}=\left\{u_{i}\right\}-\omega_{i}\left[K_{i}\right]^{-1}\left(\left[K_{i}\right]^{-1}\left\{u_{i}\right\}-\{q\}\right)
$$

here $\omega_{i}$ is the iteration coefficient.

\subsubsection{Convergence criteria}

When the method is adopted to solve the nonlinear contact problem, the convergence of the iteration needs to be considered at every step [18-22]. Assume $\left\{q_{i}\right\}$ is the exerted load, $\left\{p_{i}\right\}$ is the force vector balanced with internal force, then $\left\{q_{i}\right\}-\left\{p_{i}\right\}$ is the unbalanced force. Let $\lambda_{F}$ represents convergence tolerance of unbalanced force, then the convergence of iteration may be judged through the comparison of the unbalanced force and exerted load as follows

$\{q\}-\left\{p_{i}\right\} \leq \lambda_{F}\{q\}$

here $\left\{p_{i}\right\}=\left[K_{i}\right]\left\{u_{i}\right\}$. 


\section{Evaluation of the variables of the system}

In the vacuum picking process, the picked cardboard slides relatively to the stock and the baffles under the action of the suckers, so the dynamic friction between the contact surfaces are considered. Besides, the variables of the system including baffle height, back pressure are analyzed through the following simulations.

The coordinate system shown in Fig. 4 is established to facilitate the following discussion. Here, $L$ is the length of the cardboard, $H$ is its width, $L_{v}$ is the distance between the position line of the suckers and the side of the cardboard with zero abscissa. The baffles respectively constrain the cardboard in z-direction.

In the simulations, the baffles are fixed in all directions, while the stock may move in $z$-direction. The central points of the suckers are selected as their control node Pilot, and the loads represented by $z$-direction displacements are exerted by them step by step. The cardboard is bent gradually, resulting shrinking along the $x$-direction.

\section{1 x-dimension baffle height}

\subsubsection{Settings}

The height of the baffles is $5 \mathrm{~mm}$, the dynamic friction coefficient between the cardboard and the baffles is 0.6 , the dynamic friction coefficient between the cardboard and the stock is 0.3 , the magazine is inclined at an angle of $30^{\circ}$, the distance between the position line of the suckers and the side of the cardboard with zero abscissa is $L / 2$.

\subsubsection{Results}

The Von Mises stress and $x$-direction displacement of the cardboard are shown in Fig. 5. They are symmetrically distributed with respect to the position line of the suckers.

Therefore, six evenly distributed points of the cardboard at $x=0$ are selected and marked as A, B, C, D, E, F. The $y$-direction intervals between adjacent points are $H / 5$, and the coordinates of point $A$ are $(0,0,0)$. Taking $1 \mathrm{~mm}$ as load gain, the loads are exerted by the Pilot of the suckers. The $x$-direction displacements of the six points corresponding to each load are picked up to calculate the relative deviations. It can be seen from Table 2 that the maximum relative displacement deviation is only $0.26 \%$, so the $x$-direction displacement of the observed side may be represented by the average displacement of the six points.

In this way, the $x$-direction displacements of the observed side under the variety of loads are derived through simulations. In order to intuitively analyze the simulation results, the data is dotted in a coordinate system as shown in Fig. 6a. It can be seen that a quadratic polynomial curve is chosen to fit the dots and the fitting degree of the curve is good. Therefore, the relation between the $x$-direction displacements of the observed side and the loads exerted by the Pilot of the suckers may be further expressed by a quadratic polynomial as follows

$U(x)=-0.00625 Q(z)^{2}+0.5 Q(z)$

here $U(x)$ represents the $x$-direction displacements of the observed side, $Q(z)$ is the loads exerted by the Pilot of the suckers.

Similarly, the $z$-direction displacements of the cardboard at $x=L / 5$ under the variety of loads are derived through

Fig. 4 Coordinate system

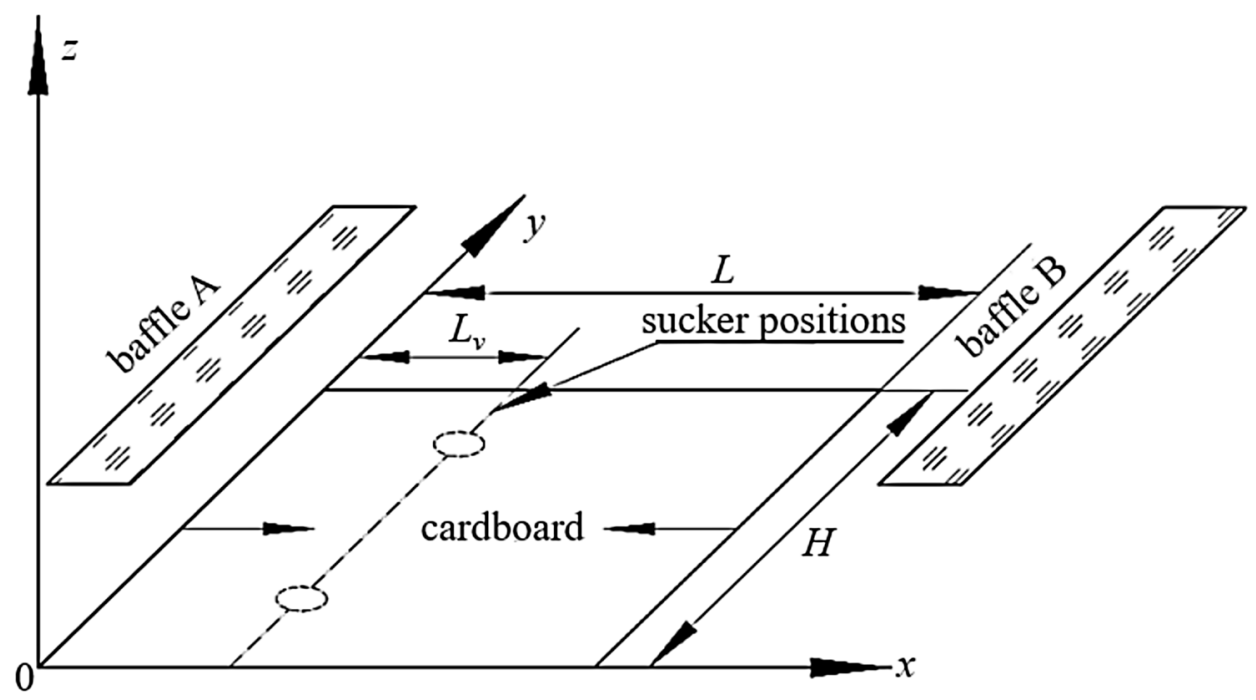




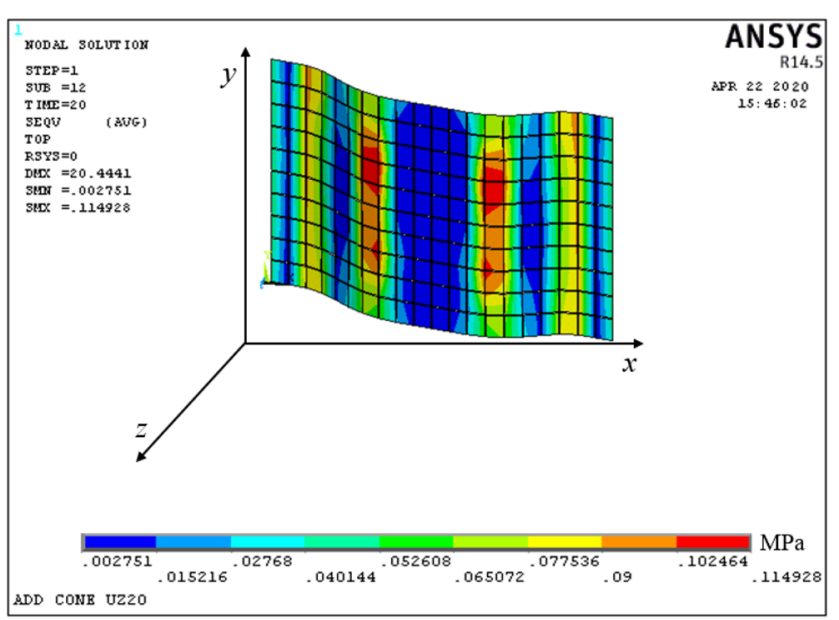

(a) Von Mises stress

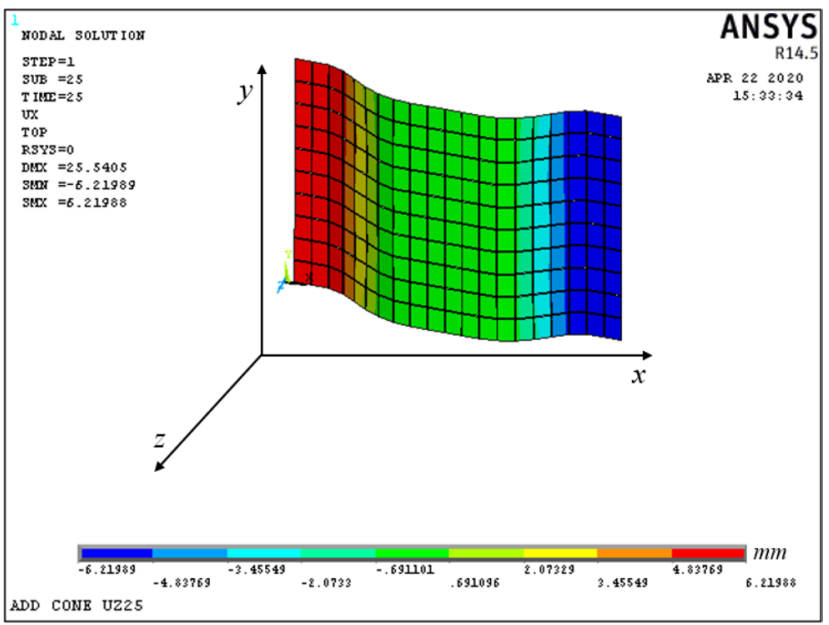

(b) $x$-direction displacement

Fig. 5 Distribution of stress and $x$-direction displacement when $L_{v}=L / 2$

Table 2 Relative displacement deviations when the load is $10 \mathrm{~mm}$

\begin{tabular}{lllllll}
\hline Points & A & B & C & D & E & F \\
\hline Relative deviations & 0 & $0.25 \%$ & $0.24 \%$ & $0.26 \%$ & $0.255 \%$ & $0.252 \%$ \\
\hline
\end{tabular}

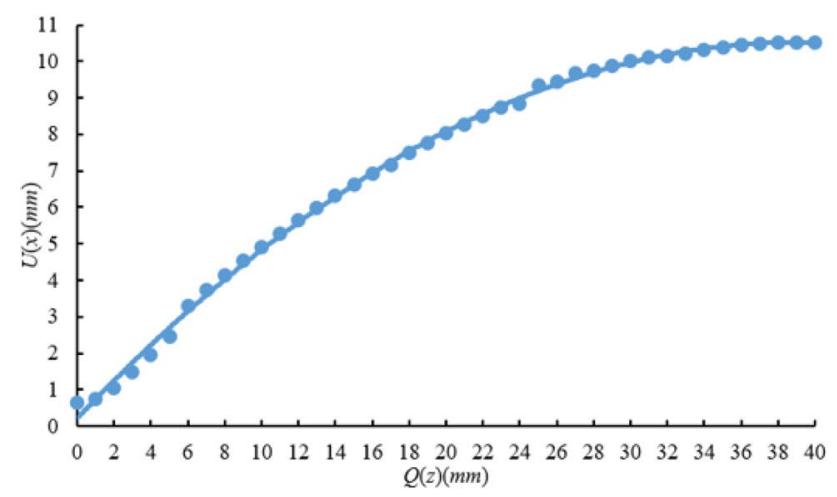

(a) $x$-direction displacements under different loads

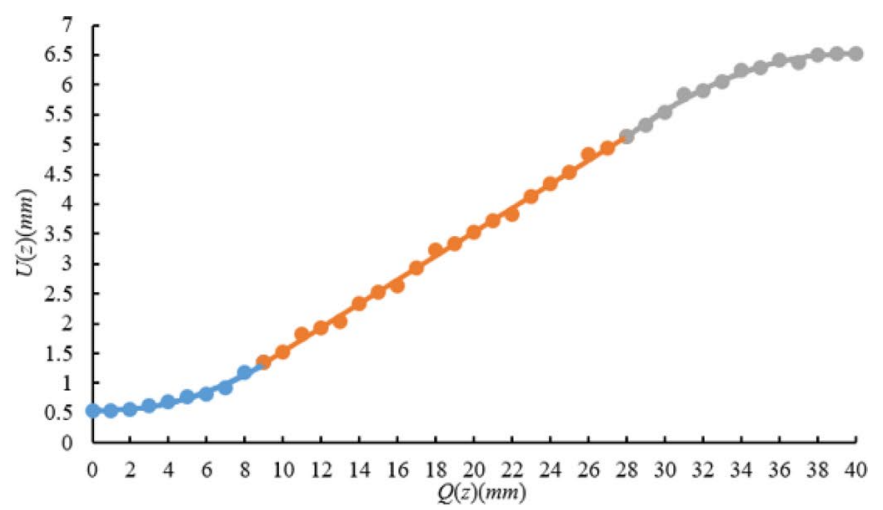

(b) $z$-direction displacements under different loads

Fig. 6 Displacements under loads

simulations. The data is dotted in a coordinate system as shown in Fig. $6 \mathrm{~b}$. It can be seen that three segmental curves are chosen to fit the dots and the fitting degree of the curves is good. Therefore, the relation between the $z$-direction displacements of the cardboard at $x=L / 5$ and the loads exerted by the Pilot of the suckers may be further expressed by Piecewise functions as follows

$$
\left\{\begin{array}{ll}
U(z)=0.01 Q(z)^{2} & 0 \leq Q(z) \leq 9.5 \\
U(z)=0.2 Q(z)-1 & 9.5<Q(z) \leq 28.9 \\
U(z)=-0.01(Q(z)-40)^{2}+6 & 28.9<Q(z) \leq 40
\end{array}\right\}
$$

here $U(z)$ represents the $z$-direction displacements, $Q(z)$ is the loads exerted by the Pilot of the suckers. 
Fig. 7 Maximum Von Mises stress at each step

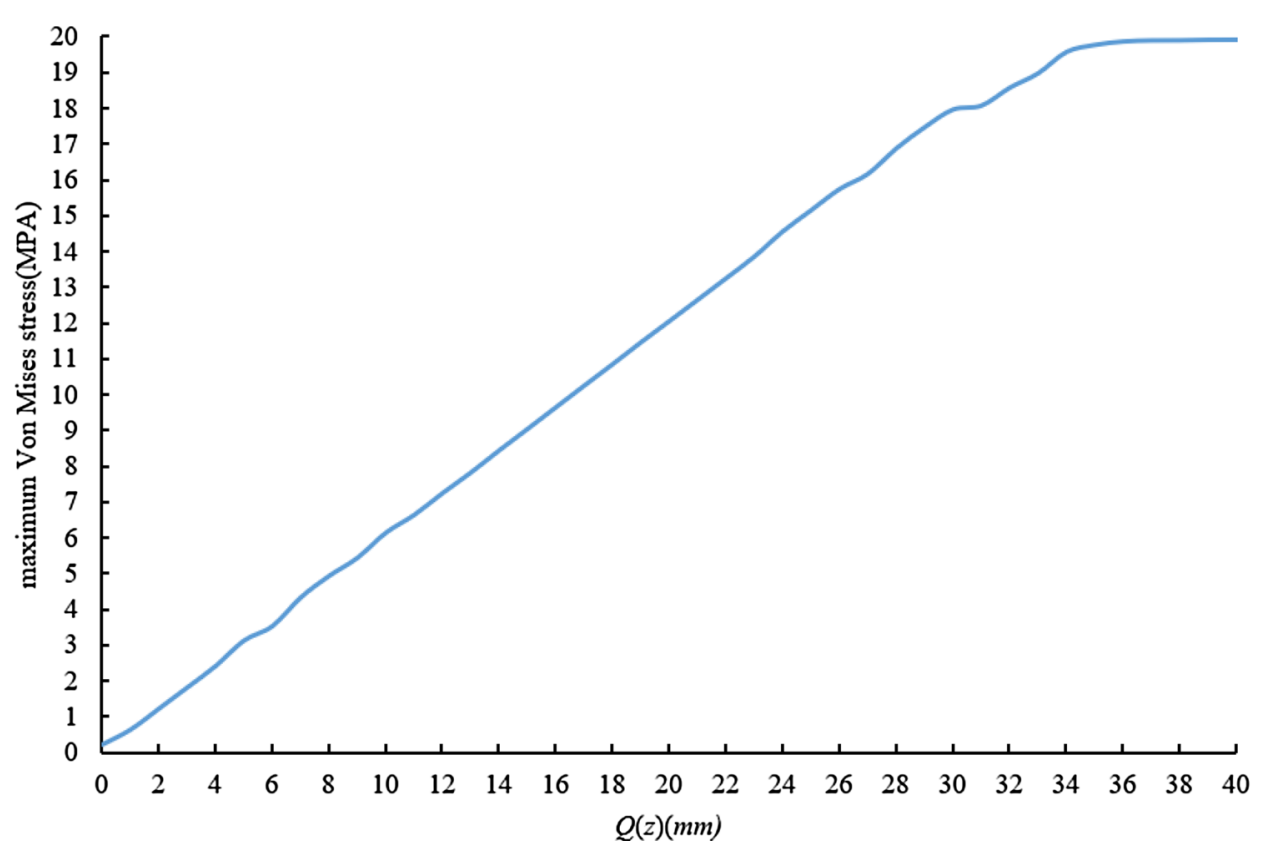

By analyzing the stress distributions of the cardboard under the variety of loads, it is found that the distribution areas of the maximum Von Mises stress are basically stationary, but its values change. It can be seen from Fig. 7 that the maximum Von Mises stress of the cardboard rises with the increase of the loads, while the yield stress of the cardboard itself is constant $18.07 \mathrm{MPa}$. If the maximum Von Mises stress of the cardboard exceeds its yield stress, the cardboard will undergo plastic deformation. So, it should be ensured that the cardboard can break away from the constraint of the baffles when the maximum Von Mises stress of the cardboard is still less than its yield stress. That is to say, the $x$-dimension baffle height of the baffles should be smaller than the $x$-direction displacement of the observed side at the beginning of yielding deformation. Considering the material specifics of the cardboard, the yield stress of the cardboard cannot be utilized to the maximum, so in practical design it is usually multiplied by a coefficient whose value is smaller than 1 .

\subsection{Back pressure}

\subsubsection{Settings}

When the magazine is inclined at a certain angle, the stock will exert back pressure on the cardboard to be fed due to its own gravity. So even back pressure is exerted on the stock, its values are listed in Table 3 . The dynamic friction coefficient between the cardboard and the baffles is 0.6 , the dynamic friction coefficient between the cardboard and the stock is 0.3 , the $x$-dimension heights of the baffles are $2 \mathrm{~mm}, 3 \mathrm{~mm}, 4 \mathrm{~mm}, 5 \mathrm{~mm}, 6 \mathrm{~mm}, 7 \mathrm{~mm}$ and $8 \mathrm{~mm}$ respectively, the inclination angles of the magazine are $30^{\circ}, 45^{\circ}$ and $60^{\circ}$ respectively.

\subsubsection{Results}

The $z$-direction displacements of the cardboard to be fed at $x=L / 2$ under the effect of the gravity are derived through simulations. The data is dotted in a coordinate system as shown in Fig. 8. It can be seen from Fig. 8 that the $z$-direction displacements of the cardboard to be fed increase with the decrease of the $x$-dimension baffle height when the inclination angle of the magazine is constant, and the $z$-direction displacements of the cardboard to be fed increase with the increase of the inclination angle of the magazine when the $x$-dimension baffle height is constant.

It can be inferred that a certain inclination angle of the magazine is beneficial to the close contact between the cardboard to be fed and the suckers, but the $z$-direction displacements of the cardboard to be fed will expand. It will lead to plastic deformation of the cardboard if the inclination angle is large or the storage
Table 3 Back pressure values corresponding to inclination angles

\begin{tabular}{llll}
\hline Inclination angles & $30^{\circ}$ & $45^{\circ}$ & $60^{\circ}$ \\
\hline Back pressure & $6.96 \times 10^{-4} \mathrm{~N} / \mathrm{mm}^{2}$ & $9.84 \times 10^{-4} \mathrm{~N} / \mathrm{mm}^{2}$ & $1.208 \times 10^{-3} \mathrm{~N} / \mathrm{mm}^{2}$ \\
\hline
\end{tabular}


Fig. 8 Inclination angles vs z-direction displacements

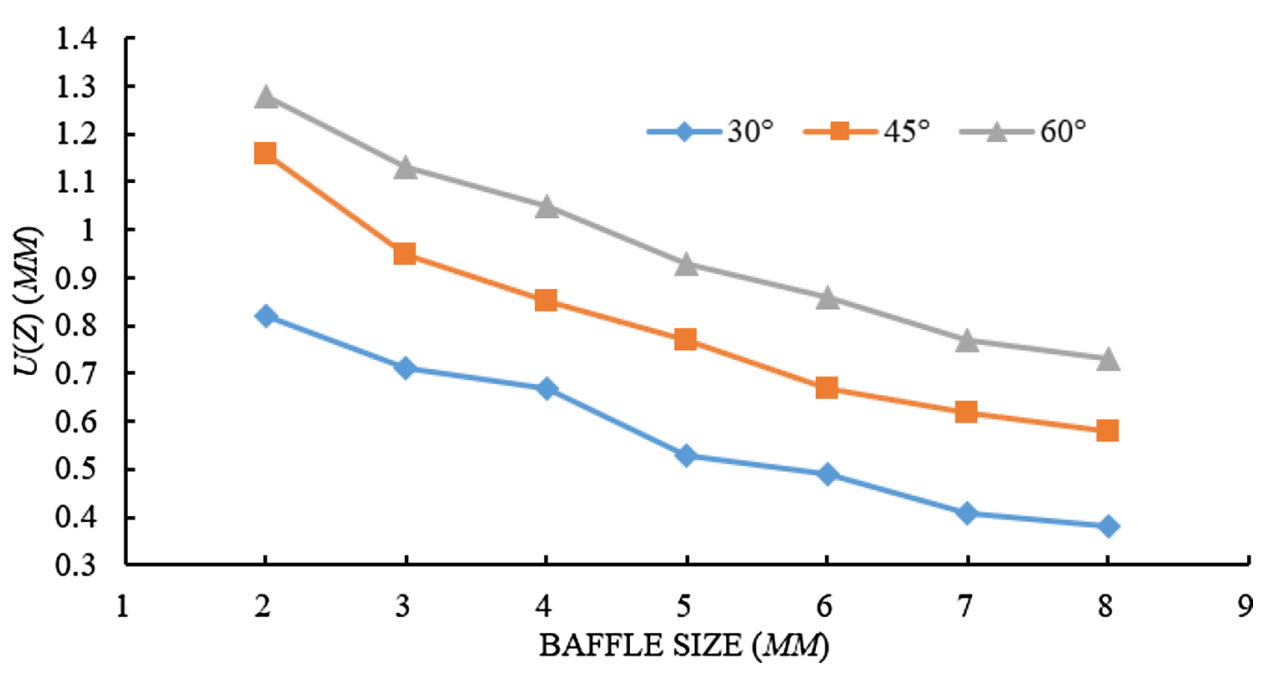

time is long. The baffles should be as narrow as possible to facilitate feeding, but at the same time it will lead to $z$-direction displacement expansion of the cardboard to be fed under the action of gravity, even plastic deformation after a long storage time.

\subsection{Friction}

\subsubsection{Settings}

The inclination angle of the magazine is $30^{\circ}$, the $x$-dimension baffle height is $5 \mathrm{~mm}$, the $z$-direction load exerted by the suckers is $10 \mathrm{~mm}$, the position line of the suckers is at $x=2 L / 5$, the dynamic friction coefficient between the cardboard and the baffles is 0.6, the dynamic friction coefficients between the cardboard and the stock are $0.2,0.3,0.4,0.5,0.6,0.7$ and 0.8 respectively.

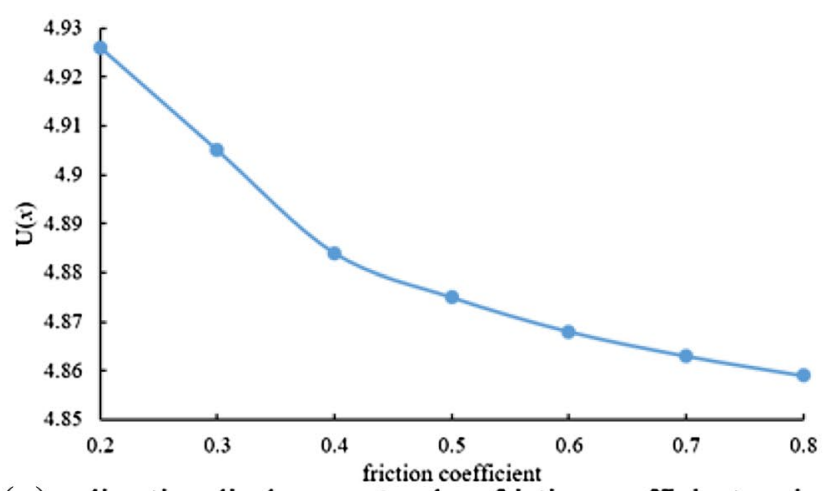

(a) $x$-direction displacements when friction coefficient varies

\subsubsection{Results}

The $x$-direction displacements at $x=0$ and $z$-direction displacements at $x=L / 5$ of the cardboard to be fed is derived through simulations. The data is dotted in a coordinate system as shown in Fig. 9. It can be seen from Fig. 9 that with the increase of the dynamic friction coefficient between the cardboard and the stock, the $x$-direction displacements of the cardboard to be fed decrease, while the $z$-direction displacements increase. It can be inferred from Figs. 6 and 7 that the maximum Von Mises stress of the cardboard rises with the increase of the $z$-direction displacements. Therefore, in order to ensure that the cardboard break away from the constraint of the baffles before yielding deformation, the dynamic friction coefficient between the cardboards should not be too large. On the other hand, if the friction coefficient between the cardboards is too small, it may cause the cardboard to slide down under the action of gravity, resulting in multiple feeds or disorder.

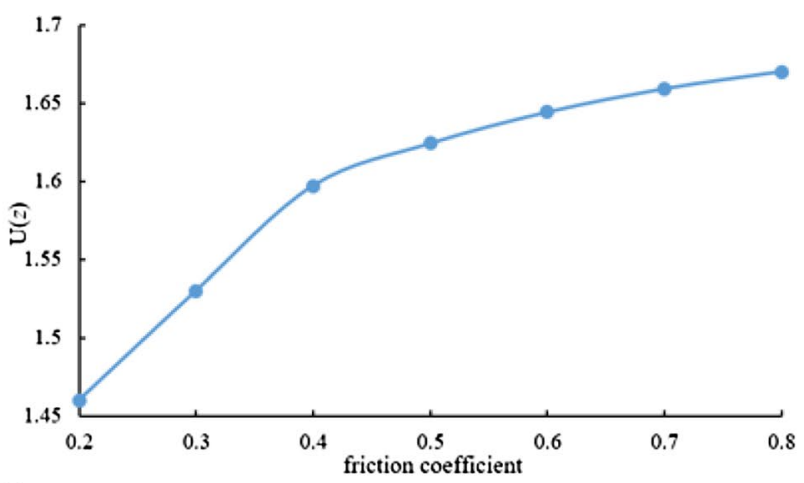

(b) $z$-direction displacements when friction coefficient varies

Fig. 9 Displacements when friction coefficient varies 


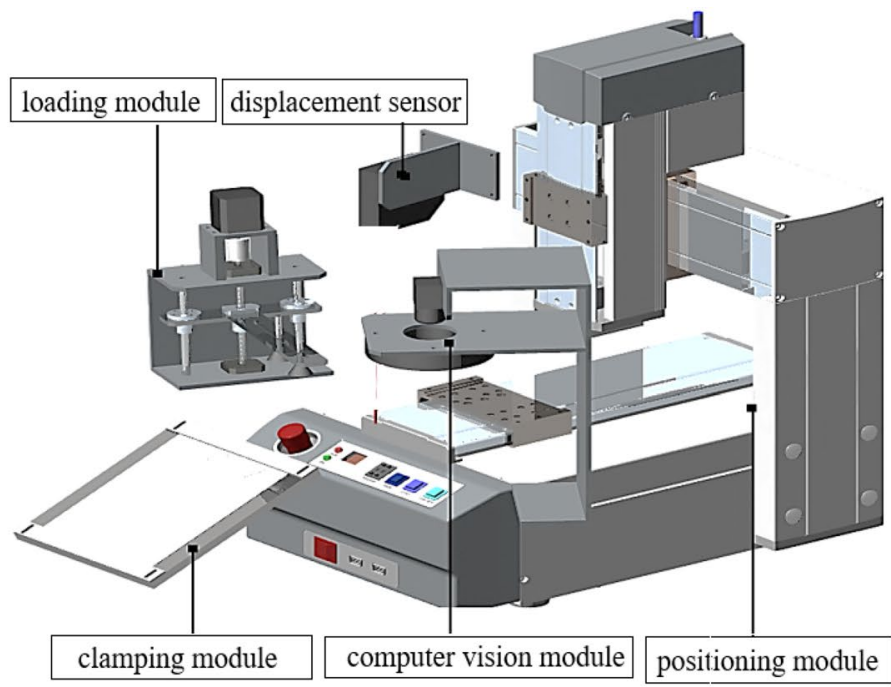

(a) exploded view

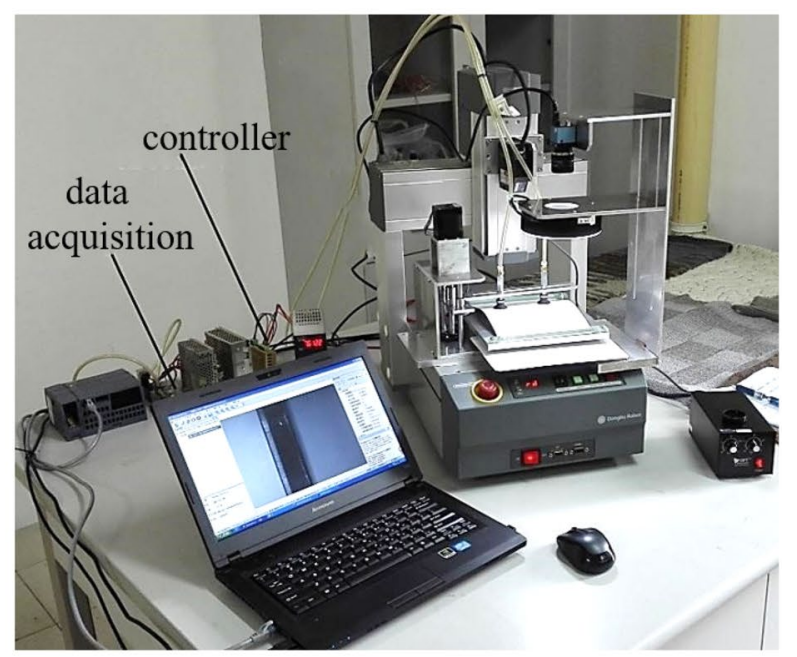

(b) working state

Fig. 10 Experimental platform

\section{Experiments}

Experiments are carried out on the experimental platform shown in Fig. 10 to verify the above simulation methods and simulation results. The positioning module is a DTR-T series robot which realizes precise control and cooperative action of $x, y$ and $z$ axes to locate specific points. The displacement sensor which is installed on the $z$-axis mounting base of the positioning module adopts a LK-G series laser displacement sensor to measure the $z$-direction displacements of the observed points in the cardboard placing process. The loading module is installed on the $z$-axis mounting base of the positioning module and composed of power element, linear transmission element, suckers and rack. The power element is a subdivided stepping motor, the linear transmission element is a compact ball screw pair, the rack is made of aluminum parts and the SMC suckers are made of rubber. With the help of the stepping motor, $z$-direction loads are exerted to the cardboard step-by-step by the loading module. The clamping module is mainly composed of bottom plate and the baffles. The bottom plate is made of aluminum workpieces with good surface quality and tilted at a certain angle. The baffles are made of white transparent acrylic plate so as to be easy for visual acquisition. The pre-tightening spiral spring together with screws is installed between the baffles and the bottom plate to adjust the pressure. The computer vision module which is composed of visual acquisition components and mounting racks detects the $x$-direction displacements of the cardboard. During the cardboard picking process, the loading module exerts $z$-direction loads to the cardboard and the computer vision module takes images of the observed side. The images are collected by the data acquisition module and then processed on PC to calculate the $x$-direction displacements of the observed side.

The same settings as the above ANSYS simulation process are used to carry out the experiments, and the same data processing methods as the simulations are adopted. The temperature in the experiment room is constantly kept at $24{ }^{\circ} \mathrm{C}$ by the air conditioner, the humidity in the experiment room is $60 \%$, and the moisture content of the board is $8 \%$. No airflow is directed to the working area of the experimental platform.

\subsection{Experiments of loading}

In order to compare the experiment results and simulation results more intuitively, they are dotted in the same coordinate system. When the $x$-dimension baffle height of the clamping module is $5 \mathrm{~mm}$, the dynamic friction coefficient between the cardboard and the baffles of the clamping module is 0.6 , the dynamic friction coefficient between the cardboard and the stock is 0.3 , the clamping module is inclined at an angle of $30^{\circ}$, the distance between the position line of the suckers and the side of the cardboard with zero abscissa is $L / 2$, the experiment results and simulation results are shown in Fig. 11a and $b$. When the inclination angle of the clamping module is $30^{\circ}$, the $x$-dimension baffle height of the clamping module is $5 \mathrm{~mm}$, the $z$-direction load exerted by the suckers of the loading module is $10 \mathrm{~mm}$, the position line of the suckers is at $x=2 L / 5$, the dynamic friction coefficient between the cardboard and the baffles of the clamping module is 0.6 , 


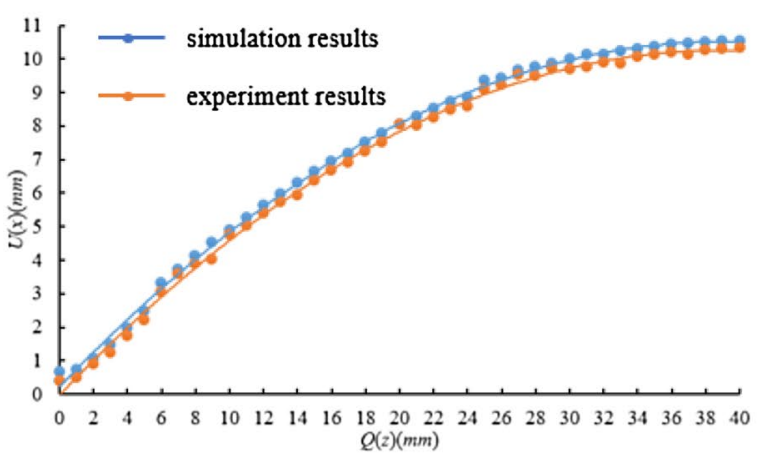

(a) $x$-direction displacements under different loads

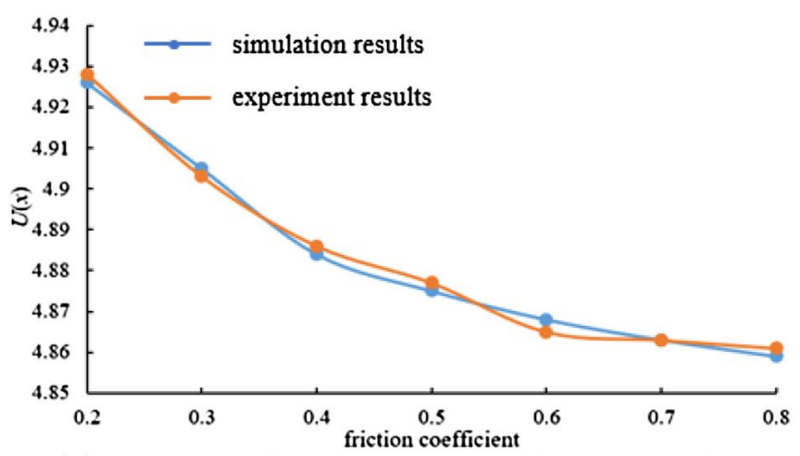

(c) $x$-direction displacements when friction coefficient varies

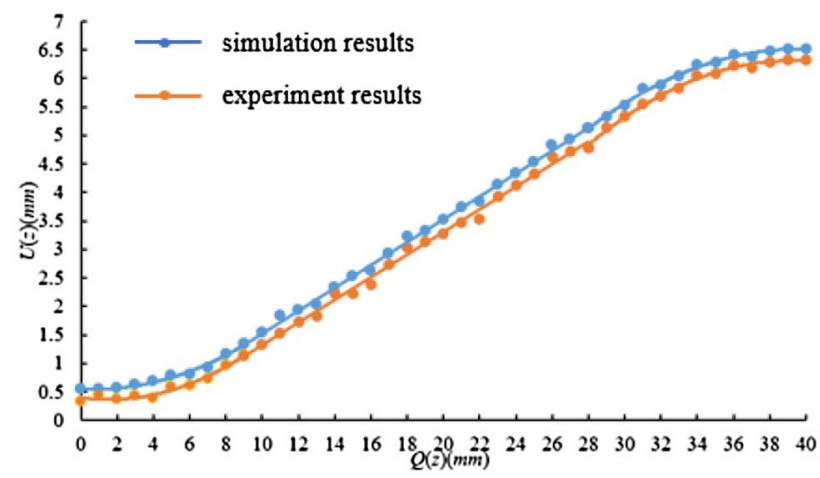

(b) $z$-direction displacements under different loads

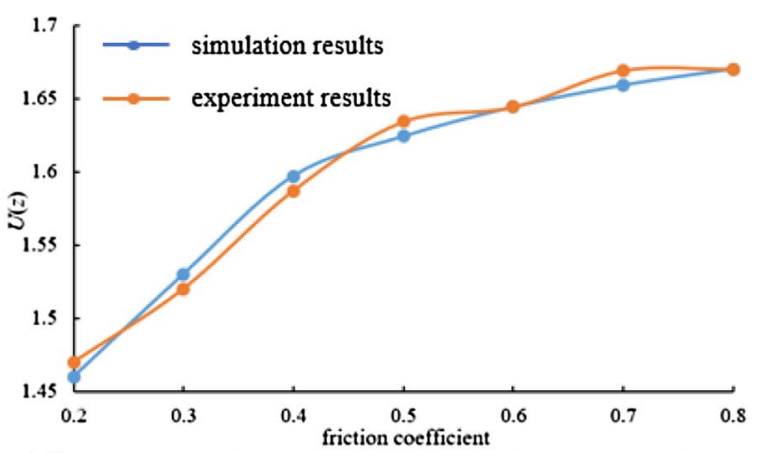

(d) $z$-direction displacements when friction coefficient varies

Fig. 11 Comparison of experiment results and simulation results

the dynamic friction coefficients between the cardboard and the stock are $0.2,0.3,0.4,0.5,0.6,0.7$ and 0.8 respectively which are achieved by using the corresponding cardboards, the experiment results and simulation results are shown in Fig. 11c and d. It can be seen that the experiment results are very close to the simulation results.

\subsection{Experiments of cardboard picking}

In order to further verify the results of the simulations and experiments above, the experiments of cardboard picking are carried out on the above experimental platform.

(1) $x$-dimension baffle height

\subsubsection{Settings}

The position line of the suckers is at $x=L / 2$, the inclination angle of the clamping module is $30^{\circ}$, the dynamic friction coefficient between the cardboard and the baffles is 0.6 , the dynamic friction coefficient between the cardboard and the stock is 0.3 , the $x$-dimension baffle heights are $10 \mathrm{~mm}, 20 \mathrm{~mm}, 25 \mathrm{~mm}$ and $35 \mathrm{~mm}$ respectively.

\subsubsection{Results}

The picking operation is repeated 200 times respectively, the results of the operation are defined as picking-out (success, damage, disorder and multiple feeds) and not-picking-out, as shown in Fig. 12. It can be seen that the ratio of pickingout increases with the decrease of the $x$-dimension baffle heights when they are less than $25 \mathrm{~mm}$, but the ratio of disorder and multiple feeds increases slightly too. The reason is that small $x$-dimension baffle heights are beneficial to absorption of the cardboards, at the same time, they will cause larger $z$-direction displacements, even lead to plastic deformation. The ratio of picking-out is very low and the ratio of damage is very high when the $x$-dimension baffle heights are greater than $25 \mathrm{~mm}$. The reason is that the maximum stress exceeds its yield stress when the cardboard breaks away from the constraint of the baffles.

(2) Friction

\subsubsection{Settings}

The position line of the suckers is at $x=L / 2$, the inclination angle of the clamping module is $30^{\circ}$, the $x$-dimension 

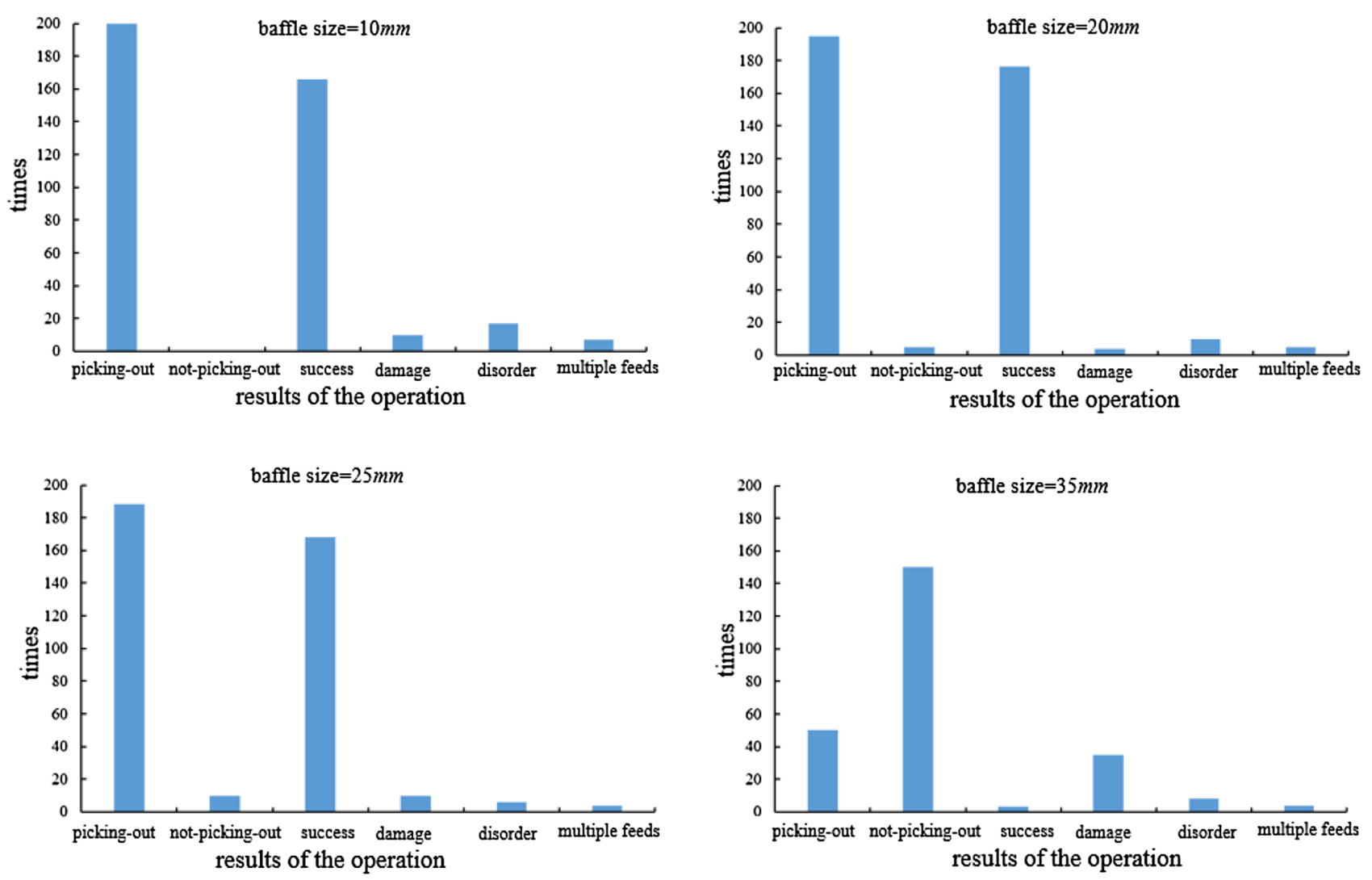

Fig. 12 Results of the operation when the $x$-dimension baffle heights vary

baffle height is $5 \mathrm{~mm}$, the dynamic friction coefficient between the cardboard and the baffles is 0.6 , the dynamic friction coefficients between the cardboard and the stock are $0.2,0.4,0.6$ and 0.8 respectively which are achieved by using the corresponding cardboards.

\subsubsection{Results}

The picking operation is repeated 200 times respectively, the results of the operation are defined as picking-out (further divided into success, damage, disorder, multiple feeds) and not-picking-out, as shown in Fig. 13. It can be seen that the ratio of picking-out increases with the decrease of the dynamic friction coefficients, but the ratio of disorder and multiple feeds increases slightly too. The reason is that small dynamic friction coefficients are conducive to the cardboard to break away from the constraint of the baffles, at the same time, they will cause the cardboard to slide under the action of gravity, resulting in disorder and multiple feeds. On the other hand, the ratio of picking-out decreases and the ratio of damage rises greatly with the increase of the dynamic friction coefficients. The reason is that the maximum stress exceeds its yield stress when the cardboard breaks away from the constraint of the baffles.

\section{Discussions}

Biancolini [2], Hua [4], Luong [6] and Li [8] adopted Finite Element Method and experiments to study the yielding behavior of corrugated paper packages too, which is of some reference value from the perspective of research method for this paper. Wen [3], Wang [7] and Guo [9] tested the mechanical behavior of different paperboards, it inspired the experiment design of this paper. Moreover, the research results of the cited literature focus on the mechanical features of fiber-based material such as different paperboards. However, in this paper it studies the mechanical behavior of the cardboard during the specific vacuum picking process, considering the main variables of the system. The results reveal the role of baffle height, back pressure and friction in cardboard vacuum picking system, which is of some practical value for the implementation of vacuum picking board sheets from in-feed magazines on many types of packaging machinery. 

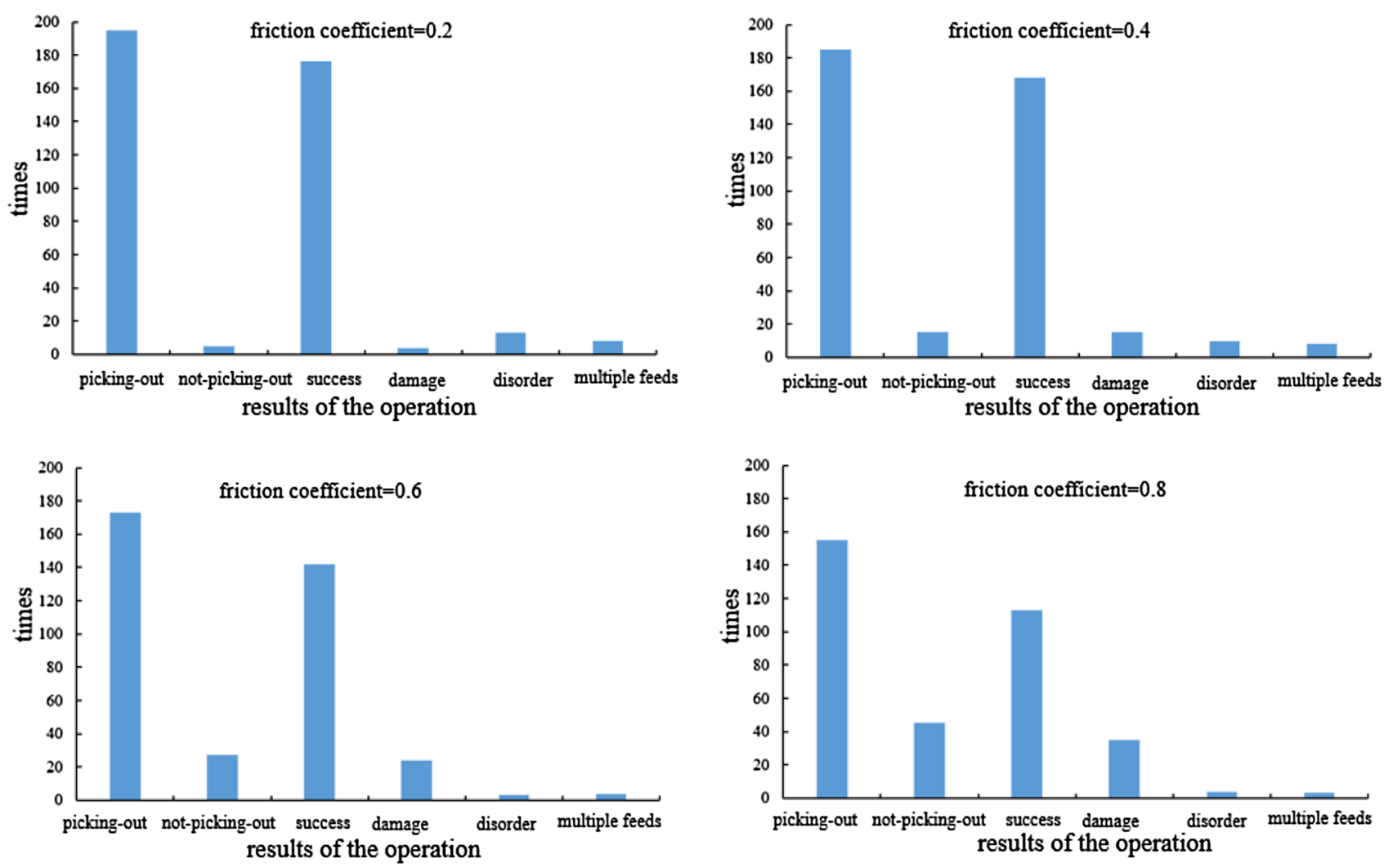

Fig. 13 Results of the operation when the dynamic friction coefficients vary

\section{Conclusions}

Baffle height, back pressure and friction between sheets are all thought to be critical in successful operation of vacuum picking of sheet board. The cardboard whose stiffness and elasticity are limited is chosen as an example, and the variables in the vacuum picking system are evaluated through simulations and experiments. It is found that $x$-dimension baffle height, magazine inclination angle and dynamic friction coefficient interact with each other in successful operation of cardboard picking. This study is of some practical value for the design of vacuum picking of board sheets from in-feed magazines on many types of packaging machinery.

However, there are some limitations too. The automatic picking system of the lining plate which plays the role of shape retention and tension maintenance in the pantyhose packaging is studied, so only simple cardboard sheets are used in this paper. However, for the transferability of the results to wider applications, it should be noted that corrugated paperboards with incisions are more widely used in packaging field, so the pick and pull system for the paperboards with incisions still needs to be further studied in the future.
Funding This work was supported by the National Natural Science Foundation of China (No. 52005338).

\section{Declarations}

Conflict of interest On behalf of all authors, the corresponding author states that there is no conflict of interest.

Open Access This article is licensed under a Creative Commons Attribution 4.0 International License, which permits use, sharing, adaptation, distribution and reproduction in any medium or format, as long as you give appropriate credit to the original author(s) and the source, provide a link to the Creative Commons licence, and indicate if changes were made. The images or other third party material in this article are included in the article's Creative Commons licence, unless indicated otherwise in a credit line to the material. If material is not included in the article's Creative Commons licence and your intended use is not permitted by statutory regulation or exceeds the permitted use, you will need to obtain permission directly from the copyright holder. To view a copy of this licence, visit http://creativecommons. org/licenses/by/4.0/.

\section{References}

1. Manich AM, Miguel R (2014) Effect of processing and wearing on viscoelastic modeling of polylactide/wool and 
polyester/wool woven fabrics subjected to bursting. Text Res J 84(18):1961-1975

2. Biancolini ME, Brutti C (2003) Numerical and experimental investigation of the strength of corrugated board packages. Packag Technol Sci 16(2):47-60

3. Wen BS (2012) Experimental investigation of flexure properties for high-strength corrugated composite paperboard. Appl Mech Mater 200:175-179

4. Hua GJ, Shen Y, Zhao D (2017) Experimental and numerical analysis of the edge effect for corrugated and honeycomb fiberboard. Strength Mater 49(1):188-197

5. Pathare PB, Berry TM, Opara UL (2017) Experimental investigation of compression strength of ventilated corrugated citrus packaging. Nephron Clin Pract 2(1):22-27

6. Luong VD, Bonnin AS (2021) Finite element and experimental investigation on the effect of repetitive shock in corrugated cardboard packaging. J Appl Comput Mech 7(2):820-830

7. Wang ZW, Sun YC (2018) Experimental investigation on bending fatigue failure of corrugated paperboard. Packag Technol Sci 31(9):601-609

8. Li Y, Stapleton SE, Simon JW (2016) Experimental and numerical study of paperboard interface properties. Exp Mech 56(8):1-12

9. Guo Y, Xu W, Fu Y (2014) Dynamic shock cushioning characteristics and vibration transmissibility of X-PLY corrugated paperboard. Shock Vib 18(4):525-535

10. Park J, Kim G, Kim H (2011) Characteristics of vibration transmissibility for corrugated paperboard. J. Fac. Agric. Kyushu Univ. 56(2):327-333

11. Bivainis V, Jankauskas V (2015) Impact of corrugated paperboard structure on puncture resistance. Mater Sci 21(1):57-61

12. Liu WC, Huang J (2021) Experimental and crystal plasticity modelling study on the crack initiation in micro-texture regions of Ti-6Al-4V during high cycle fatigue tests. Int J Fatigue 148:106-123

13. Alain L, Elaine $P$ (2017) On the equilibria and qualitative dynamics of a forced nonlinear oscillator with contact and friction. Discrete Contin Dyn Syst Ser S 9(2):501-527
14. Li J, Zhao YL, Zhu HP (2015) Bifurcation of an SIS model with nonlinear contact rate. J Math Anal Appl 423(2):1119-1138

15. Blockmans B, Tamarozzi T, Naets F (2015) A nonlinear parametric model reduction method for efficient gear contact simulations. Int J Numer Meth Eng 102(5):1162-1191

16. Zhao YS, Yang C, Cai LG (2016) Surface contact stress-based nonlinear virtual material method for dynamic analysis of bolted joint of machine tool. Precis Eng 43:230-240

17. Wang XP, Liu G, Ma SJ (2016) Dynamic analysis of planar mechanical systems with clearance joints using a new nonlinear contact force model. J Mech Sci Technol 30(4):1537-1545

18. Zhang Y, Wang JH, Guu SM (2015) Convergence criteria of the generalized Newton method and uniqueness of solution for generalized equations. J Nonlinear Convex Anal 16(7):1485-1499

19. Mou XN, Lu LX, Zhang W (2019) Characterization of in-plane load bearing of a honeycomb paperboard. Packag Technol Sci 32:23-37

20. Xu W, Tomasz K (2015) Coupling of system thermal-hydraulics and monte-carlo code: Convergence criteria and quantification of correlation between statistical uncertainty and coupled error. Ann Nucl Energy 75:377-387

21. Stoica G (2017) An extension of a convergence criteria. Gazeta Matematica 36:20-23

22. Sun ZX, Zhu T, Wang XH (2017) Optimization of convergence criteria for fragmentation methods. Chem Phys Lett 687:163-170

Publisher's Note Springer Nature remains neutral with regard to jurisdictional claims in published maps and institutional affiliations. 